\title{
DEVELOPING STREET DESIGN FOR DIRE DAWA CITY TO ENHANCE THERMAL COMFORT
}

\author{
Girma, Asmamaw Ayele \\ School of Civil Engineering and Architecture, \\ Dire Dawa Institute of Technology / Dire Dawa University \\ Dire Dawa, Ethiopia
}

\begin{abstract}
This study discusses the contribution of street design, i.e. aspect ratio or height-to-width ratio $(H / W)$ and solar orientation towards the development of a comfortable microclimate at street level for pedestrians. The investigation was carried out by using the threedimensional numerical model ENVI-met, which simulates the microclimatic changes within urban environments in a high spatial and temporal resolution. Model calculations are run for a typical summer day in May 10, 2016 in Dire Dawa, Ethiopia $\left(9.6^{\circ} \mathrm{N}, 41.85^{\circ} \mathrm{E}\right.$, and $1200 \mathrm{~m}$ a.s.l.), a region characterized by a hot and dry climate. Symmetrical urban canyons, with various height-to-width ratios (i.e. H/W 1/4 0.5, 1, and 2) and different solar orientations (i.e. E-W, N-S, NE-SW and NW-SE), have been studied. Special emphasis was placed on a human biometeorological assessment of these microclimates by using the physiologcally equivalent temperature (PET). The analysis discussed the hourly temperature variation, humidity, wind speed and solar radiation in detail. Sun path and shadow length calculation for Dire Dawa city was made to compare the comfort of each street. Street width, building height, aspect ratio and street orientation were taken as major variables for the analysis.

The results showed contrasting patterns of thermal comfort between shallow and deep urban streets as well as between the various orientations studied in a typical $12 \mathrm{~m}$ street.

Keywords - Urban Micro-Climate, Urban Design, PET, ENVI-met, Thermal Comfort, Street Canyon.
\end{abstract}

\section{INTRODUCTION}

A city is a public place. That is the streets and squares appear to be carved from an original block of material (Building facades). Street is a road with urban character for movement between places, the principle lines of communication between places - a two-dimensional ribbon, running on the surface of the landscape, carried over it by bridge or beneath by tunnel. Its more common meaning is a road in a town or village, comparatively wide as opposed to a lane or alley [9].
Mayer H, et al (1987) states, unattractive urban areas are one of the main reasons why people prefer to live in the outskirts of cities rather than in their centre. As an effect, a continuous expansion of the urbanized areas known as urban sprawl can be observed. There are many environmental and economical drawbacks associated with this sprawl effect, from which land consumption and traffic generation are probably the most obvious. In order to counteract this effect, urban planners wish to bring life back into the cities and attract more people to live inside the city core.

Mayer H, et al (1987), Outdoor thermal comfort of cities mainly depends on air temperature, humidity, wind speed and solar radiation. The orientation of streets, size and related plants and street side buildings plays great role in adjusting the outdoor thermal comfort.

Santamouris M. et al (1999) describes outdoor activities in hot climatic areas depend on the external thermal environment. Apart from the thermal environment, several other parameters had been shown to be of significance to the subjective assessment and satisfaction of the outdoor environment, such as context (design, function), environmental interaction (lighting, acoustics, air quality), and psychological parameters (expectations, experience, time of exposure, perceived control, environmental stimulation.

The American Society of Heating, Refrigeration and Air conditioning Engineers ASHRAE et al (2001) states, thermal comfort for a person is that condition of mind which expresses satisfaction with the thermal environment. It is concerned with predicting the sets of temperature, humidity and air speed corresponds to those natural feelings and human adaptation to it. Oke T. et al $(1977,1988)$ laterally defined comfort as the absence of discomfort. People feel uncomfortable when they are too hot or too cold, or when the air is odorous and stale. Positive comfort conditions are those that do not distract by causing unpleasant sensations of temperature, drafts, humidity, or other aspects of the environment. Ideally, in a properly conditioned space, people should not be aware of equipment noise, heat, or air motion.

Arnfield J. et al (1990), if air temperature (Ta), wind speed (v), vapor pressure (VP), and the mean radiant temperature ( $\mathrm{T}_{\mathrm{mrt}}$ are known, it is possible to calculate a thermal comfort 
index PET. PET is defined as the air temperature at which, in a typical indoor setting $\left(\mathrm{T}_{\mathrm{mrt}}=\mathrm{Ta} ; \mathrm{VP}=12 \mathrm{~h} \mathrm{~Pa} ; \mathrm{v}=0.1 \mathrm{~m} / \mathrm{s}\right)$, the heat balance of the human body is maintained with core and skin temperatures equal to those under the conditions will be assessed. PET has the unit degree Celsius $\left(1^{\circ} \mathrm{C}\right)$ and can, therefore, be more easily interpreted.

Dire Dawa city, in which located at hot semi arid temperature and at altitude of $1200 \mathrm{~m}$ above sea level. The city is characterized by high population density and rapidly expanding urban land. However like most of Ethiopian cities, streets and blocks are designed following less consideration on micro climatic aspects. This study discussed the contribution of street design, i.e. aspect ratio (or height-to-width ratio, $\mathrm{H} / \mathrm{W}$ ) and solar orientation, towards the development of a comfortable microclimate at street level for pedestrians. The investigation was carried out by using the three-dimensional numerical model ENVI-met, which simulates the microclimatic changes within urban environments in a high spatial and temporal resolution. Model calculations were run for a typical summer day in Dire Dawa, Ethiopia $\left(9.6^{0} \mathrm{~N}\right.$, $\left.41.85^{\circ} \mathrm{E}\right)$, a region characterized by a hot and dry climate. Symmetrical urban canyons, with various height-to-width ratios (i.e. $\mathrm{H} / \mathrm{W}=, 0.5,1,1.5$ and 2) and different solar orientations (i.e. E-W, N-S, NE-SW and NW-SE), were studied. Special emphasis was placed on a human biometeorological assessment of these microclimates by using the physiologically equivalent temperature.

\section{METHOD}

The outdoor thermal comfort on street level needs to simulate micro climatic change using ENVI - met soft ware and the temperature variation using PET standards.

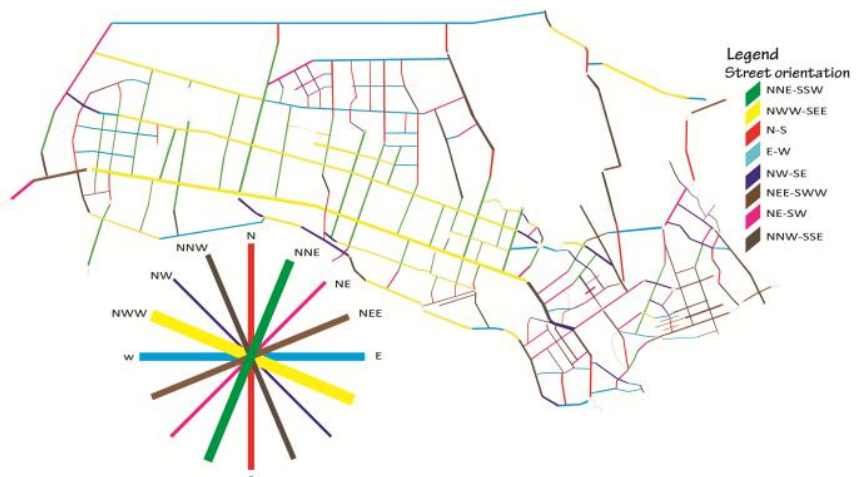

N.B. $1 \mathrm{~mm}$ line width: 6 number of streets (Source: own analysis)

Fig.1. Street orientations analysis

In order to use these tools it needs to gather and compile quantitative data about hourly temperature, humidity, wind speed, solar radiation, building height and surface material, street width and orientation and plant type and availability. For analyzing the physical conditions (streets, and urban forms) of streets of Dire Dawa city, representative sample streets need to be identified. These streets were screened out using purposive sampling. For this the streets of Dire Dawa city were grouped using cardinal direction. The parameters were orientation, street size (width), adjacent building height and volume of pedestrian.

From figure 1 above, of all streets of Dire Dawa city $28.35 \%$ of streets oriented to NWW - SEE (Yellow), 19.4\% are NNE - SSW (Green) and $11.36 \%$ oriented to E - W (Blue). This means $59.11 \%$ of the existing streets are oriented to NWW, NNE and E-W.
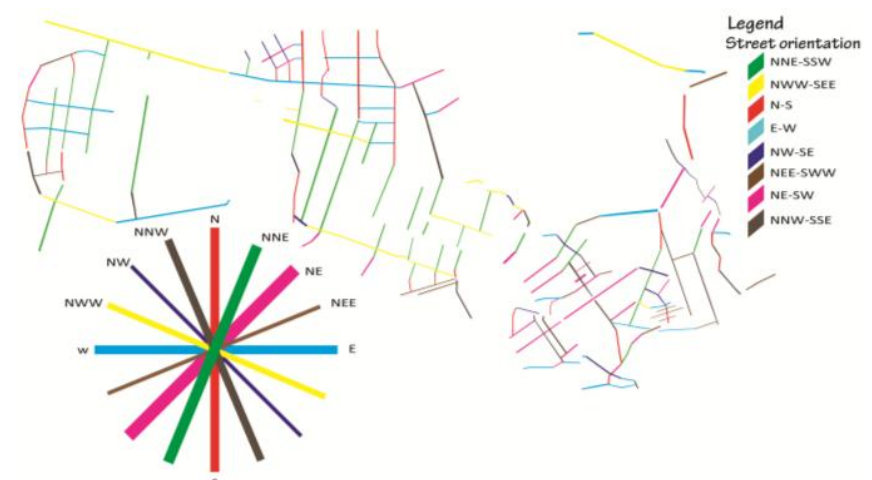

N.B. $1 \mathrm{~mm}$ line width: 6 number of streets (Source: own analysis)

Fig.2. $12 \mathrm{~m}$ Street orientations analysis

For the study, the $12 \mathrm{~m}$ wide streets were chosen since it covers the highest percentage from the whole streets and their orientation is figured (Fig 2) below. Of all the $12 \mathrm{~m}$ wide streets in Dire Dawa city, 17.61\%, 16.97\%, 14.47\%, $14.47 \%$ are oriented to $\mathrm{NE}-\mathrm{SW}, \mathrm{NNE}-\mathrm{SSW}, \mathrm{E}-\mathrm{W}$ and $\mathrm{N}-\mathrm{S}$ respectively. This means $63.52 \%$ of the existing streets are oriented to NE, NNE, N-S and E-W and the NE - SW orientation found to be dominant orientation.

Based on the pedestrian movement, four streets out of the existing $12 \mathrm{~m}$ wide streets were systematically and purposively sampled to check physiological equivalent temperature (PET) and ENVI-met. The streets were identical in width with different building height, street orientation and plantation. The selected streets are shown below (Fig 3 and Table 1) with their respective orientation, aspect ratio and adjacent building height. The analysis was done quantitatively using a three dimensional modeling software, ENVI-met, which simulates the microclimatic changes within urban environments in a high spatial and temporal resolution [6] [7].

Table.1.Street Identification

\begin{tabular}{|c|l|r|c|c|c|}
\hline No & Name & Size & Orientation & $\begin{array}{c}\text { Aspect ratio } \\
(\mathrm{H} / \mathrm{W})\end{array}$ & Building Height \\
\hline 1 & Street A & $12 \mathrm{~m}$ & $\mathrm{~N}-\mathrm{S}$ & $1 / 2$ & $\mathrm{G}+0$ \\
\hline 2 & Street B & $12 \mathrm{~m}$ & NE-SW & 1 & $\mathrm{G}+2$ \\
\hline 3 & Street C & $12 \mathrm{~m}$ & E-W & $3 / 2$ & $\mathrm{G}+3$ \\
\hline 5 & Street D & $12 \mathrm{~m}$ & NW-SE & 2 & $\mathrm{G}+6$ \\
\hline
\end{tabular}




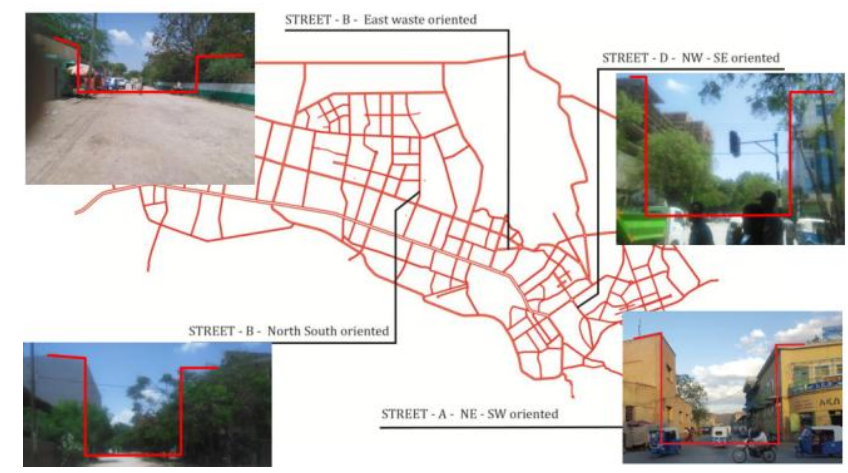

Fig.3. Sampled streets

The solar analysis was made using the following three equations as described in the following steps (Eq. 1, 2 and 3).

Step -1: calculating the declination $(\sigma)$ which is the same for all locations

$$
\sigma=23.45(360 / 365(\mathrm{~N}+284))
$$

Where $\mathrm{N}=$ Julian yean starting from January 1

Step-2: Calculate the altitude (A) of the sun using the following formula

$A=\sin ^{\wedge}(\sin \sigma \sin \theta+\cos \sigma \cos \theta \cos \omega)$

Where, $\sigma=$ latitude of the location; $\omega=$ hour angle (which is $\omega=\cos ^{\wedge}(-\tan \Theta \tan \sigma)$

Step-3: calculate the Azimuth of the sun for each hour

$\mathrm{AZI}=\arcsin \left[\left(\cos \sigma^{*} \sin \omega\right) / \cos \mathrm{ALT}\right]$ and to get the day length $=2 / 15 \omega$

\section{RESULT AND DESCUSSION}

\subsection{General condition for the Simulation}

In this section, detail information about the site location, street size and type, duration of simulation and other relevant information for the simulation are discussed in detail.

Various aspect ratios of the sampled streets were considered so as to simulate the micro climatic conditions for different orientations. The vertical resolution for simulation at street level was taken at two meters above ground level with one meter depth (fig 4 and Table 2). This is to address the outdoor thermal comfort of human being on pedestrians.

\subsection{Material Surfaces and Physical Condition}

Most of the walls of buildings are of hollow concrete block and masonry structures. The walls of sampled streets characterized by thick masonry wall structure, plastered surface with white, yellow or orange paint. All of selected streets have asphalted vehicular carriage way and cobble stone paved pedestrian way with evenly spaced street side plants except for $\mathrm{N}-\mathrm{S}$ and $\mathrm{NW}-\mathrm{SE}$ streets, which are randomly planted. The roofs of building along street $\mathrm{D}$ are made of concrete; other buildings in the rest of other streets have roofs made of corrugated iron sheet.
Table.2. General conditions for the simulation

\begin{tabular}{l|l}
\hline $\begin{array}{l}\text { Location } \\
\text { Climate type }\end{array}$ & $\begin{array}{l}\text { Dire Dawa City, Ethiopia, } 9.6^{\circ} \mathrm{N}, 41.85^{\circ} \mathrm{E} \\
\text { Simulation day }\end{array}$ \\
$\begin{array}{l}\text { Simulation duration } \\
\text { typical date of hottest month, } 10^{\text {th }} \text { of May } \\
\text { Spatial resolution }\end{array}$ & $1 \mathrm{~m}$ horizontally, $2 \mathrm{~m}$ vertically \\
Street width & 12 meters \\
Building height, H & $6,12,18$, and $24 \mathrm{~m}$ \\
Building length, $\mathrm{L}$ & $6 \mathrm{H}(\approx$ urban canyon) \\
Building width, W & Variable $(12-15 \mathrm{~m})$ \\
Wind speed & $14 \mathrm{~m} / \mathrm{s}$ at $10 \mathrm{~m}$ above ground level (Constant) \\
Wind direction & Perpendicular to street axis \\
Air humidity & VP $=62 \%$ \\
Heat transmission & Wall: U-value $=1.7 \mathrm{~W} / \mathrm{m} 2 \mathrm{~K}$ \\
& Roof: $\mathrm{U}$-value $=2.2 \mathrm{~W} / \mathrm{m} 2 \mathrm{~K}$ \\
Indoor temperature & $294.15 \mathrm{~K}\left(21^{\circ} \mathrm{C}\right)$, constant \\
Albedo & Asphalt road $=0.1$ \\
& Block walls $=0.3$ \\
& Roof $=0.15$ \\
\hline
\end{tabular}

Source: own analysis and Ali-Toudert

\begin{tabular}{|l|c|c|c|c|c|}
\hline & Street A & Street B & Street C & Street D & Remark \\
\hline & & & & & \\
\hline
\end{tabular}

Source: own analysis and Ali-Toudert

Fig.4. Simulated street canyons description

\subsection{Sunpath and Solar Shadow}

Arvind Krishan et al (2001) illustrates in the thermal (climatic) design of buildings, the sun is the decisive factor since solar radiation reflectivity and emissivity on different surfaces gives a desirable heating effect in winter, but it can cause severe overheating in summer. To understand this phenomenon, studying the local path of the sun and its shadow is necessary. Therefore draw the path of the sun over Dire Dawa city, calculating the declination, altitude, azimuth and hour angle are necessary. The site is found at $9.6^{\circ} \mathrm{N}$ latitude and $41.85^{\circ} \mathrm{E}$ longitude. Using this location of Dire Dawa, all angles were calculated using equation $1-3$. As tabulated in Table 3, 1 meter tall sundial or gnome standing up right on a perfectly horizontal surface has the tabulated shadow length. This was 
done for June, September and December to understand the different length of the days throughout the year. Since these months, describe the extreme day length of the year.

Table.3.Altitude, Azimuth and solar shadow length of 1meter pole in different months

\begin{tabular}{|c|c|c|c|c|c|c|c|c|c|c|}
\hline \multirow{2}{*}{$\begin{array}{l}\text { HOUR(Loca } \\
\text { I time) }\end{array}$} & \multirow{2}{*}{$\begin{array}{l}\text { color } \\
\text { codes }\end{array}$} & \multicolumn{3}{|c|}{ 22-Jun } & \multicolumn{3}{|c|}{ 22-Sep } & \multicolumn{3}{|c|}{ 22-Dec } \\
\hline & & ALT & A & SL & ALT & A & SL & ALT & A & SL \\
\hline 10:00 PM & & 55.05 & 62.487 & 0.7 & 57.447 & 104.57 & 0.638 & 43.997 & 136.392 & 1.036 \\
\hline 11:00 PM & & 67.46 & 49.873 & 0.42 & 71.278 & 118.52 & 0.339 & 52.682 & 152.536 & 0.762 \\
\hline 12:00 PM & & 75.74 & 13.653 & 0.25 & 80.674 & 171.47 & 0.164 & 56.853 & 175.388 & 0.653 \\
\hline 1:00 AM & $=$ & 72.42 & 323.24 & 0.32 & 73.591 & 236.51 & 0.294 & 54.857 & 199.765 & 0.704 \\
\hline 2:00 AM & - & 61.27 & 302.04 & 0.55 & 60.046 & 253.66 & 0.576 & 47.558 & 218.49 & 0.914 \\
\hline 3:00 AM & & 48.19 & 294.57 & 0.89 & 45.608 & 260.53 & 0.979 & 37.116 & 230.665 & 1.321 \\
\hline 4:00 AM & $=$ & 34.58 & 291.91 & 1.45 & 30.935 & 264.55 & 1.669 & 25.042 & 238.383 & 2.14 \\
\hline \multicolumn{11}{|c|}{ NB. ALT = Altitude, $\mathrm{A}=$ Azimuth, $\mathrm{SL}=$ Shadow Length } \\
\hline
\end{tabular}

Source: own analysis

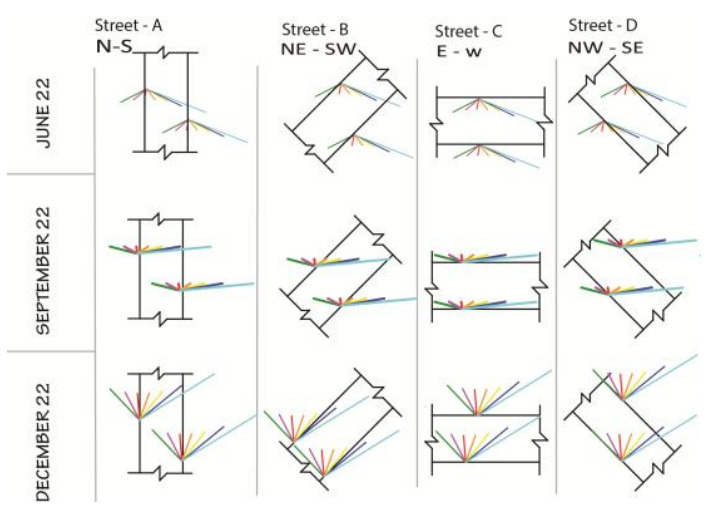

Fig.5. Shadow length from both sides of selected streets between 10:00am to 4:00pm. Source: own analysis

Arvind Krishan et al (2001) and Nagara K. et al (1996) determined the overheated period, i.e. the dates and times when shading should be provided, one can understand the temperature profile. This can be taken as the time when the monthly mean temperature is higher than the lower comfort limit. The daily temperature profile should be looked at to ascertain the hours when shading is necessary. This overheated period should also take into account the type of building, the amount of internal heat gain and even the relationship of solar gain to the building mass. However, for this study, only the height of the building and the shadow length created on the streets were considered. Fig 4 shows the length of shadow for a gnome at both sides of the streets for the identified months, days and times of the year for different orientation of the $12 \mathrm{~m}$ wide street. Except the E - W street (street C), the rest could provide shade to the street throughout the year. Shade provided on Street $\mathrm{C}$ was only from one side during the entire year and maximum on December.

\subsection{EXISTING MiCROCLIMATE ANALYSIS}

Actual hourly micro climatic condition measurement was taken so as to reach the real feeling on day to day human activities. This will help to compare with the ENVI-met microclimatic outputs and farther more to check the outdoor thermal comfort. For checking the outdoor thermal comfort of each street, it needs on spot measurement of temperature, humidity and solar radiation. The temperature and wind speed of each street were measured using thermometers for the typical harsh day of the year on May 10, 2016 for the period that spans from 10:00 AM to 4:00 PM at an hour interval. The observed temperature was compared to the simulated value using ENVI-met.

For the four selected streets the hourly temperature was measured at one hour interval as shown in fig 6 . It was found that the air temperature ranges from $31^{\circ} \mathrm{C}$ to $35^{\circ} \mathrm{C}$ at $10: 00$ $\mathrm{AM}$ and 2:00 PM respectively. The highest temperature for street $\mathrm{B}$ and $\mathrm{C}$ and $\mathrm{A}$ and $\mathrm{D}$ were found to be $35^{\circ} \mathrm{C}$ and $34^{\circ} \mathrm{C}$ respectively between 1:00 PM and 3:00 PM. The NE - SW and $\mathrm{E}-\mathrm{W}$ streets were found to attain high temperature between 1:00 PM and 2:00 PM $\left(35^{\circ} \mathrm{C}\right)$.

For all selected streets the wind speed was measured in an hour interval as shown in fig 7 . The maximum and minimum wind speeds were recorded on street $\mathrm{B}$ and $\mathrm{C}$ which is $10.05 \mathrm{~m} / \mathrm{s}$ and $6.1 \mathrm{~m} / \mathrm{s}$ at 3:00 PM and 4:00 PM respectively. The local wind speed is higher on streets B and D which are oriented North east - South west and North West - South east accordingly. The wind speed is low on Street C.

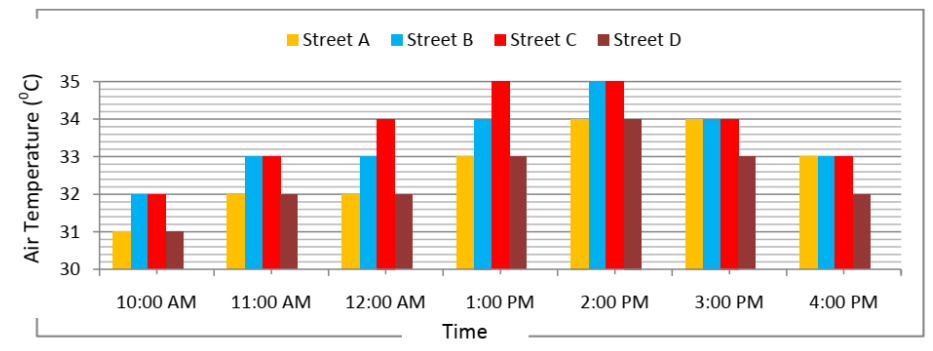

Fig.6. Hourly temperature variation on all streets

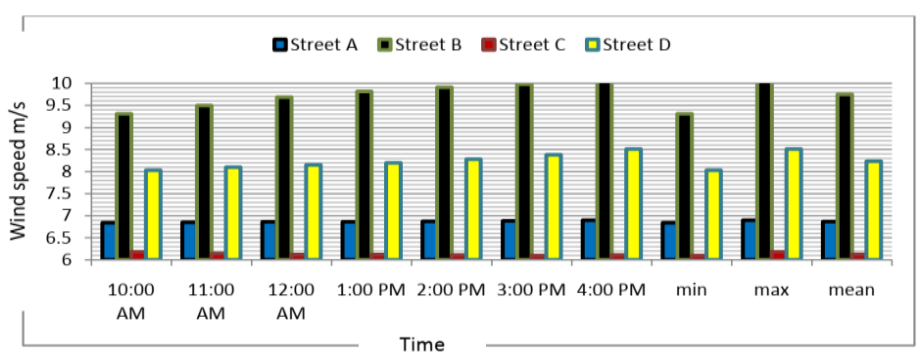

Fig.7. Hourly wind speed variation on all streets

\subsection{ENVI-MET SIMULATION ANALYSIS}

In this study, the 3D model ENVI-met, version 4.0 was used. Bruse M. et al (1998, 1999), ENVI-met model is software, used for the analysis of microclimate complex urban structure. The major advantage of ENVI-met is that it is one of the first models that seeks to reproduce the major processes in the atmosphere that affect the microclimate, including the simulation of wind flows, turbulence, radiation fluxes, temperature and humidity, on a well-founded physical basis (i.e. the fundamental laws of fluid dynamics and thermodynamics). 
ENVI-met simulates the microclimatic dynamics within a daily cycle in complex urban structures, i.e. buildings with various shapes and heights as well as vegetation. Its high spatial and temporal resolution enables a fine understanding of the microclimate at street level. It also requires relatively little input parameters, and calculates all important meteorological factors, e.g. air and surface temperatures, wind speed and direction, air humidity, short-wave and long-wave radiation fluxes, as well as the mean radiant temperature needed for comfort analyses. The analysis outputs are clearly presented by graph and pictures following the Leonardo output display software, which is one of the tools of ENVI-met. Even if the model analyzes more than ten conditions, only the wind speed, air temperature, humidity and solar radiation analyses were taken by comparing with PET to check the thermal comfort of each street.

\subsubsection{STREET - A /North-South Street}

The air temperature (Ta) of street $A$ has been analyzed using ENVI-met model as shown in figure 8. The analysis shows that, for the existing aspect ratio the maximum Ta was attained at $1: 00 \mathrm{PM}, 33.78^{\circ} \mathrm{C}$. Air temperature in the street was simulated from the periods 10:00 AM to 4:00 PM, the maximum air temperature found to be at 1:00 PM and the minimum was at 10:00 AM. The analysis was made for an area of $60 \mathrm{~m}$ by $60 \mathrm{~m}$ which mainly focus on the selected street. The simulation of air temperature at the peak hour (1:00 PM) shows, the temperature is higher $\left(32-33.8^{0} \mathrm{C}\right)$ on barely shaded part of the street and lower $\left(29-30^{\circ} \mathrm{C}\right)$ on better shaded part of the street.

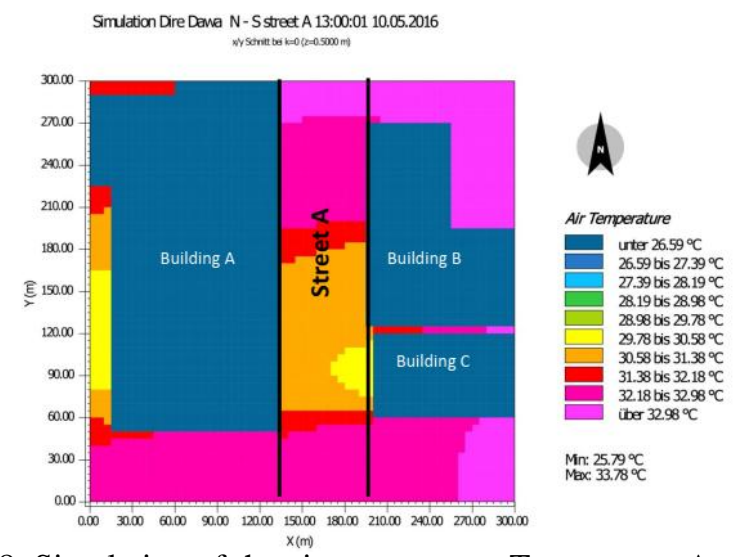

Fig.8. Simulation of the air temperature Ta on street A at 1:00 PM.

\subsubsection{STREET - B / North East - South West Street}

Similarly street B was subjected to ENVI-met analysis for the existing aspect ratio within an hour interval between 10:00AM and 4:00PM (fig. 9). The maximum temperature was found at $1: 00 \mathrm{PM}, 34.33^{\circ} \mathrm{C}$. Air temperature is above $30^{\circ} \mathrm{C}$ on all simulated time intervals. The Ta variation started at 11:00 AM and become high in the afternoon, at 2: 00 PM. For H/W 0.5 the Street, is a little bit exposed to harsh sun during November, December and January.

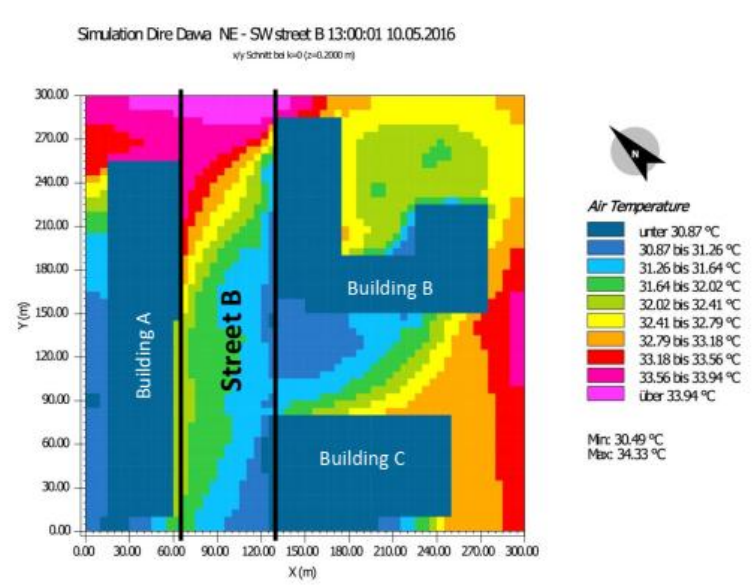

Fig.9. Simulation of the air temperature Ta on street B at 1:00 PM.

\subsubsection{STREET - C /EAST-WEST STREET}

The air temperature of street $\mathrm{C}$ also checked using ENVI-met between 10:00 AM and 4:00 PM as shown in figure 10. Street $\mathrm{C}$ is the warmest with the largest differences occurring in the afternoon around 1:00 PM $\left(34.8^{\circ} \mathrm{C}\right)$. The Ta variances start at 11:00 AM and maximum in the afternoon between 1: 00 PM to 3:00 PM. The street is highly exposed to harsh sun for a long period of time. To minimize the air temperature during peak hour (1:00 PM), extended aspect ratio should be applied on both sides of the street.

Simulation Dire Dawa E - Wstreet C 13:00:01 10.05.2016
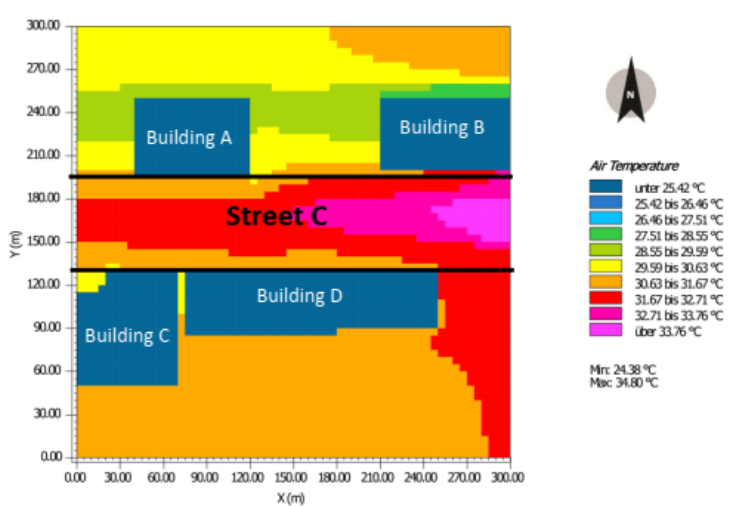

Fig.10. Simulation of the air temperature $\mathrm{Ta}$ on street $\mathrm{C}$ at 1:00 pm.

\subsubsection{STREET - D / North West -South East Street}

The ENVI-met analysis of Air temperature for street D shows, the highest temperature was recorded around the shortest building height and found to be $37.82^{\circ} \mathrm{C}$ (fig. 11). The air temperature is also higher on the street and becomes lower at the back yards. The Ta variances start at 11:00 AM just like other streets and the maximum is in the afternoon at 2:00 PM. The street has long shadow period as the result of existing high aspect ratio $\mathrm{H} / \mathrm{W}=2$, which is needed for cities like Dire 
Dawa. The minimum temperature on the selected peak hour was found to be $34.84^{\circ} \mathrm{C}$ along the street.

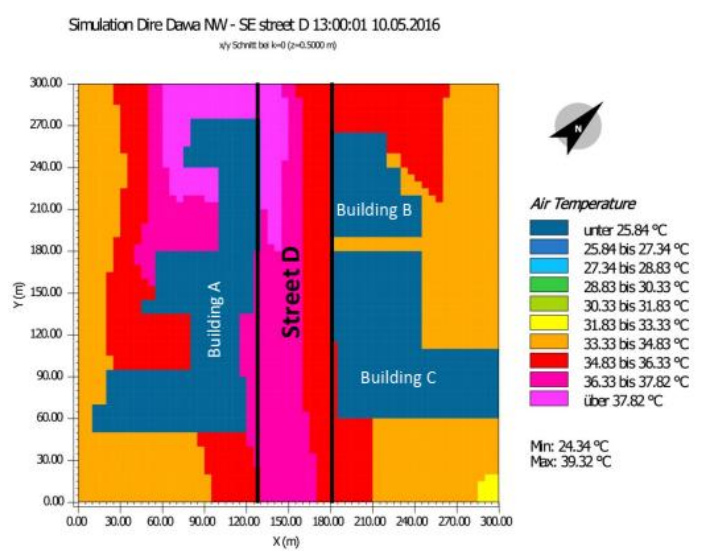

Fig.11. Simulation of the air temperature Ta on street D at 1:00 $\mathrm{pm}$

\subsection{RESULT}

\subsubsection{Sun Path}

From the sun path calculation done, by derivation of solar angle equation, altitude and azimuth of sun, it is easy to determine the length of shadow for each month throughout the year. The expression of azimuth derived from the direction of the sun which is $(\cos A Z I=(\operatorname{sinDEC}-\sin A L T * \operatorname{sinLAT}) /$ ( $\operatorname{cosLAT} * \cos$ ALT), where DEC is declination of sun, ALT is altitude and LAT is latitude).

The horizontal shadow angle has been defined as the azimuth difference: HSA = AZI - ORI where the orientation angle (ORI) is the azimuth angle of the direction a building (a facade) faces, i.e. the azimuth angle of the surface normal of that facade. This means that when AZI < ORI, the sun is to the left, or anticlockwise of the orientation, the HSA is negative. When AZI > ORI, HSA is positive, the sun is to the right, or clockwise. The result is meaningful only up to $\left|90^{\circ}\right|$. A larger value indicates that the sun is behind the facade considered and will not reach that facade. For automated calculation a check-routine must be built in: if $90^{\circ}<|\mathrm{HSA}|<270^{\circ}$ then the facade is in shade. To provide shade for the horizontal surface (streets and open spaces) it is good to use $\mathrm{SL}=\mathrm{BH} / \mathrm{tan}$ (90ALT), where (SL is shadow length, BH building height and ALT is altitude of sun).

The result is summarized for a factor of $1 \mathrm{~m}$ height on different representative months between the pick hours between 10:00 $\mathrm{AM}$ and 4:00 PM as indicated in table 4. So, the comfortable building height can be calculated by: $\mathrm{CHB}=\mathrm{SW} / \mathrm{SSL}$ where ( $\mathrm{SW}$ is street width; SSL is shortest shadow length and CHB = comfortable height of the building), this works for any of the orientation specified on cardinal direction.

Table.4. simulation of comfort street width for $1 \mathrm{~m}$ pole for representative months

\begin{tabular}{|l|c|c|c|r|r|r|c|}
\hline \multirow{3}{*}{ Month } & \multicolumn{7}{|c|}{ Comfort street width (Shadow length $x$ Height of bldg.) } \\
\cline { 2 - 8 } & $10: 00$ & $\begin{array}{c}11: 00 \\
\text { AM }\end{array}$ & $\begin{array}{c}\mathbf{1 2}: 00 \\
\text { AM }\end{array}$ & $\begin{array}{c}1: 00 \\
\text { PM }\end{array}$ & $\begin{array}{c}2: 00 \\
\text { PM }\end{array}$ & $\begin{array}{c}3: 00 \\
\text { PM }\end{array}$ & $\begin{array}{c}4: 00 \\
\text { PM }\end{array}$ \\
\hline June & $0.7 \mathrm{H}$ & $0.42 \mathrm{H}$ & $\mathbf{0 . 2 5 H}$ & $0.32 \mathrm{H}$ & $0.55 \mathrm{H}$ & $0.89 \mathrm{H}$ & $1.45 \mathrm{H}$ \\
\hline August & $0.66 \mathrm{H}$ & $0.34 \mathrm{H}$ & $\mathbf{0 . 0 8 H}$ & $0.2 \mathrm{H}$ & $0.48 \mathrm{H}$ & $0.85 \mathrm{H}$ & $1.43 \mathrm{H}$ \\
\hline September & $0.64 \mathrm{H}$ & $0.34 \mathrm{H}$ & $\mathbf{0 . 1 6 H}$ & $0.29 \mathrm{H}$ & $0.58 \mathrm{H}$ & $0.98 \mathrm{H}$ & $1.67 \mathrm{H}$ \\
\hline October & $0.72 \mathrm{H}$ & $0.47 \mathrm{H}$ & $\mathbf{0 . 3 8 H}$ & $0.48 \mathrm{H}$ & $0.75 \mathrm{H}$ & $1.19 \mathrm{H}$ & $2.03 \mathrm{H}$ \\
\hline December & $1.04 \mathrm{H}$ & $0.76 \mathrm{H}$ & $\mathbf{0 . 6 5 H}$ & $0.7 \mathrm{H}$ & $0.91 \mathrm{H}$ & $1.32 \mathrm{H}$ & $2.14 \mathrm{H}$ \\
\hline
\end{tabular}

From the table (table 4) above, the shortest shadow length recorded was at 12:00 AM for the entire year. During August the sun is at equinox, which is 0.08 meter shadow length for a unit meter building height, results in 150meter building height for 12 meter street. The longest shadow recorded was at 4:00 PM for the whole months in that the longest shadow was at December, results in 5.6 meter building height for 12 meter street. The overall average building height recommended from the result was found to be W/0.766.

Table 5 describes the minimum building height requirement for the represented months. The shade assumed without considering vegetation and extended facades. But from the result gained, it is not simple to determine the height of the building without considering the economic shadow length, on street plantations and cantilever structures. The building height gained at December is very low as compared to the height gained on August, so, one can consider the average height for the entire year.

As the meteorological data received from Jigjiga branch, the highest rainfall for Dire Dawa city was recorded on August. This results in cold microclimate as compared to other months within the year. So, there is a probability of using the second building height received from the calculation that is 75 meter during September. From this finding the economic building height from the solar shadow can be taken from the average building height of September and December which results around 46 meter ( $\mathrm{G}+13$ to $\mathrm{G}+15)$ without considering vegetation and cantilever.

Table.5. Simulation of comfort building height for $12 \mathrm{~m}$ street for representative months

\begin{tabular}{||c|c|c|c|c|c||}
\hline & \multicolumn{5}{|c||}{ building height regulation for 12 meter streets } \\
\cline { 2 - 6 } & June & August & September & October & December \\
\hline factor & 0.25 & 0.08 & 0.16 & 0.38 & 0.65 \\
\hline $\begin{array}{c}\text { building } \\
\text { height(m) }\end{array}$ & 48 & 150 & 75 & 31.6 & 18.5 \\
\hline
\end{tabular}

From fig $12 \mathrm{~N}-\mathrm{S}$ orientation was found to be the most comfortable street that gets shadow from both side of the street throughout the year. This enables the people to choose walkways following the shadow casted on the street. Streets B and D (NE - SW and NW - SE) were less comfortable as compared to $\mathrm{N}-\mathrm{S}$ street, while street $\mathrm{C}$ was totally not comfortable which gets the shadow from one side throughout the day and doesn't cover the whole of the $12 \mathrm{~m}$ street. Thus, it needs special design focus to make it climatically comfortable. 


\subsubsection{Mean Radiant Temperature}

A critical issue in extending the assessment of human comfort from indoors to outdoors is the need for the mean radiant temperature Tmrt. This quantity sums up all short-wave and long-wave radiation fluxes absorbed by a human body and affecting its energy balance.

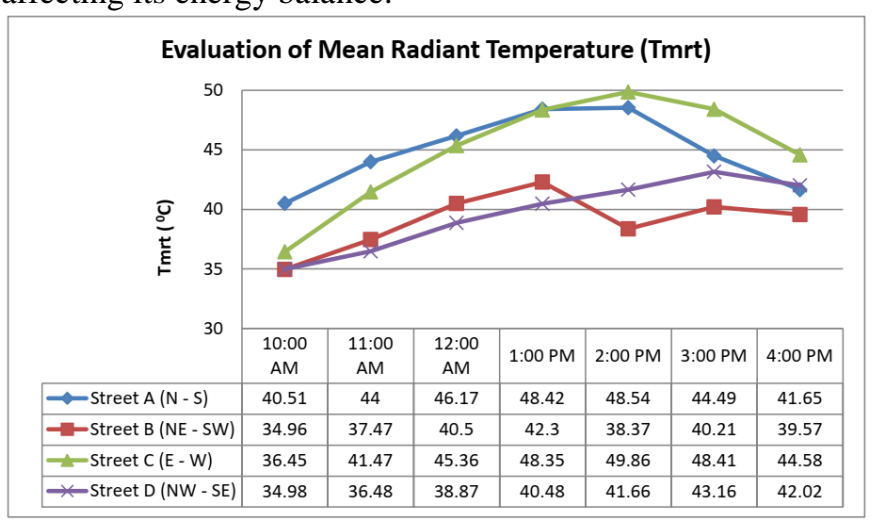

Chart.1. Evaluation of mean radiant temperature

Tmrt is the key variable in evaluating thermal sensation outdoors during the daylight hours in summer regardless of the comfort index used. However, its determination for outdoors is not obvious, particularly in complex urban environments. Mean radiant temperature is a state in which in typical indoor setting Tmrt equals to air temperature. The result of the analysis made as displayed on fig 4.2 , shows there is high difference between Tmrt and air temperature.

As expected, the mean radiant temperature Tmrt (chart 1) was noticeably lower within the urban streets than in an unobstructed location (e.g. Street D vs. Street A). The difference between sheltered and exposed measuring locations reached $8^{0} \mathrm{C}$ at the hottest time of the day (e.g. between Street $\mathrm{D}$ and $\mathrm{A}$ around 2:00 PM). The $\mathrm{N}-\mathrm{S}$ Street (Street A) experienced the highest $T \mathrm{mrt}$ values ranging between $44^{\circ} \mathrm{C}$ and $48^{\circ} \mathrm{C}$ from 1:00 PM to 4:00 PM. The high $T$ mrt values in the morning were due to the lateral irradiation of the standing person when the sun is still relatively low. In more detail, Tmrt differences between the different urban streets are clearly higher than the change in air temperature.

The lowest $T \mathrm{mrt}$ values were calculated for street B and D, which have high aspect ratios as compared to other streets. This was expected since streets B and D are covered pathways and are not directly influenced by solar radiation. At this location, Tmrt showed a 'flat' diurnal course with values varying between $34^{\circ} \mathrm{C}$ and $43^{\circ} \mathrm{C}$. Street $\mathrm{D}$ is as protected as Street B, except at midday, at which time $T \mathrm{mrt}$ reaches $43^{\circ} \mathrm{C}$. This is due to the NW-SE orientation of this urban street canyon which prevents shadowing even though the canyon is very deep.

\subsubsection{Physiological Equivalent Temperature (PET)}

The spatial visualization of thermal conditions for human biometeorological significant analysis may be obtained from spatial distribution of PET; for this hourly PET bioclimatic map is constructed (chart 2).

Generally, E - W oriented street $\mathrm{C}$ was the most uncomfortable street which has mean value of PET $30.54^{\circ} \mathrm{C}$ and NW - SE oriented street D was the most comfortable street in which the mean value of PET found to be $29.25^{\circ} \mathrm{C}$ (Table 4.3). It is possible to consider two findings here, one, since street $\mathrm{D}$ has $\mathrm{H} / \mathrm{W}=2$ in which the canyon provides long shadow for the street for long period of time as compared to others, secondly the availability of vegetation on the street and shadow results in equivalent PET throughout the day.

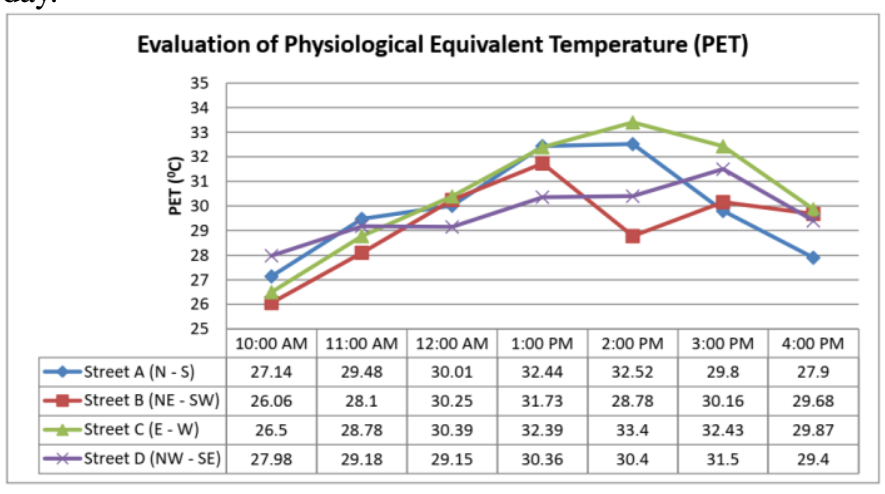

Chart.2. Evaluation of Physiological Equivalent Temperature

Even if $\mathrm{N}-\mathrm{S}$ oriented street $\mathrm{A}$ has $\mathrm{H} / \mathrm{W}=0.5$, the mean PET value for the street was not maximum like $\mathrm{E}-\mathrm{W}$ street. This indicates that compared to the analysis done for solar shadow for $\mathrm{N}-\mathrm{S}$ street, it is possible to summarize that $\mathrm{N}-\mathrm{S}$ street is also comfortable at aspect ratio $\mathrm{H} / \mathrm{W}>2$.

The most uncomfortable locations were those exposed to the sun. PET peak values, occurred in the afternoon and ranged from 33 to $35^{\circ} \mathrm{C}$ at street $\mathrm{C}$ and $34^{\circ} \mathrm{C}$ at street $\mathrm{A}$. These high values needs to be mitigated by ventilating wind speed. By contrast, the lowest PET value $\left(27^{\circ} \mathrm{C}\right)$ was determined for street B. In the early morning and late afternoon, PET did not reveal clear differences between the sites within street canyons, i.e. PET $\approx 30^{\circ} \mathrm{C}$ before $1: 00 \mathrm{PM}$ and $\approx 29^{\circ} \mathrm{C}$ after 3:00 PM. PET values decreased very slowly in the night-time and roughly equaled the air temperature at midnight.

The merged result of sun path diagram, physiological equivalent temperature (PET) and ENVI-met showed that N - $\mathrm{S}$ oriented street (street A) is the best orientation for Dire Dawa city and $\mathrm{E}-\mathrm{W}$ oriented street (street $\mathrm{C}$ ) is the most uncomfortable street. However, when the cities planed to fulfill the urban design criterions basically transportation and permeability, it is a must to create $\mathrm{E}-\mathrm{W}$ streets perpendicular to $\mathrm{N}-\mathrm{S}$ street. So, orienting arterial streets to $\mathrm{N}-\mathrm{S}$ with narrow collective streets $(\mathrm{E}-\mathrm{W})$ will be a good option to create comfortable outdoor environment for pedestrians.

The intermediate orientations NE - SW (street B) and NW SE (street D) had almost similar characteristics and with high aspect ratio H/W 2 and above, they are comfortable. 


\section{International Journal of Engineering Applied Sciences and Technology, 2019 Vol. 4, Issue 1, ISSN No. 2455-2143, Pages 6-13 \\ Published Online May 2019 in IJEAST (http://www.ijeast.com)}

\section{CONCLUSION}

As Dire Dawa has hot summers at most and few rainy months at winters, sufficient shading should be provided by trees and buildings to improve thermal comfort in summer. However, since the people have poor tolerance of hot temperature, based on the theory of thermal adaptation and according to previous studies of the local thermal comfort range on hot areas, outdoor space planning should create areas with excessive shading.

The simulations also revealed that the duration and time of day of high thermal stress, as well as the spatial distribution of peak PET values within a street canyon depend strongly on aspect ratio and street orientation.

This study quantitatively confirms that shading for both pedestrians and surrounding surfaces is crucial in mitigating human heat stress. A judicious combination of high aspect ratios and orientation, arranging galleries, planting trees, greening the facades or using other shading devices on the walls are a few possible solutions. Promoting ventilation through appropriate urban plan orientation and density is a further possibility to reduce heat stress. These were verified quantitatively to be effective for the city.

High aspect ratios were found to be an effective strategy in shortening the duration of exposure to solar radiation and mostly affected the amount of absorbed short-wave irradiance. The very high aspect ratios investigated have partly inhibited the influence of the orientation. However, it was observed that the N-S and NW -SE orientations are the most comfortable except around noon, and a NE-SW oriented street is more stressful than a NW-SE one while E - W streets were uncomfortable for large duration. This is in good agreement with results obtained by modeling [2] [3] [16].

Nikolopoulou M, et al (2001) summerizes covered streets experience the lowest PET values as the heat emitted from these surfaces is noticeably lower in comparison to other canyons and the sheltered street is almost not influenced by the daily course of solar radiation. This corroborates the usefulness of galleries as pedestrian pathways. Although nighttime outdoor comfort is of small relevance in comparison to day-time, the cooling of the houses would last longer and would extend the period of night-time discomfort indoors.

The minimum requirement for the height of building and street width were by the formula; SW $=\mathrm{BH}$ X SS (where SW is the street width, BH is building height and SS is shortest shadow). Since no shelter design can provide thermal comfortable throughout an entire year, multiple shade types and different shading levels are recommend for outdoor spaces. In this manner, user can choose what they prefer based on their desired thermal comfort level to stay on streets for a long period of time.

\section{REFERENCES}

[1] Ali Toudert, Djenane F., Bensalem M., Mayer R. 2005. Outdoor thermal comfort in the old desert city of BeniIsguen, Algeria. Climate Research (28; pp. 243-256).
[2] Ali-Toudert, Mayer H. (2005), Numerical study on the effects of aspect ratio $\mathrm{H} / \mathrm{W}$ and orientation of an urban street canyon on outdoor thermal comfort. Building Environ. (41: 94-108)

[3] Arnfield J. (1990): Street design and urban canyon solar access. Energy and Buildings (14: 117-131).

[4] Arvind Krishan, Baker Nike, Yannas Simos, Szokolay S V. (2001). Climate responsive Architecture, A design handbook for energy efficient buildings.

[5] ASHRAE, (2001), Chapter 13-measurements and instruments. In: Handbook of Fundamentals. Atlanta, ASHRAE: (p. 13.26-7).

[6] Bruse M. (1999), The influences of local environmental design on microclimate- development of a prognostic numerical Model ENVI-met for the simulation of Wind, temperature and humidity distribution in urban structures. Ph.D. Thesis, Germany: University of Bochum.

[7] Bruse M, Fleer H. (1998), Simulating surface-plant-air interactions inside urban environments with a threedimensional numerical model. Environmental Modeling Software; (13:373-84).

[8] Givoni B. (1997), Climate considerations in building and urban design. Van Nostrand Reinhold, New York

[9] Matzarakis A., Mayer H. (1996), another kind of environmental stress: thermal stress. WHO collaborating centre for air quality management and air pollution control (pp. 7-10)

[10] Mayer H, (1987). Thermal comfort of man in different urban environments. Theoretical and Applied Climatology; (38:43-49).

[11] Nagara K, Shimoda Y, Mizuno M. (1996). Evaluation of the thermal environment in an outdoor pedestrian space. Atmospheric Environment; (30:497-505)

[12] Nikolopoulou M, Baker N, Steemers K. (2001), Thermal comfort in outdoor urban spaces: understanding the human parameter. Solar Energy; (70:227-35).

[13] Nunez M, Oke T. (1977), The energy balance of an urban canyon. Journal of Applied Meteorology; (16:11-9).

[14] Oke T. (1988), Street design and urban canopy layer climate. Energy and Buildings; (11:103-13).

[15] Santamouris M., Papanikolaou N., Koronakis I., Livada I., Asimakopoulos D. (1999): Thermal and air flow characteristics in a deep pedestrian canyon under hot weather conditions. Atmos. Envir. (33: 4503-4521).

[16] Spagnolo J. \& de Dear R. (2003). A field study of the thermal comfort in outdoor and semi outdoor environments in subtropical Sydney Australia. Building and Environment, (38, 721-738). 